\title{
TITANIUM DIOXIDE/COPPER/CARBON COMPOSITES FOR THE PHOTOCATALYTIC DEGRADATION OF PHENOL
}

\author{
Stalin Coronel ${ }^{1}{ }^{2}$, Christian Sandoval Pauker ${ }^{1}$, Paul Vargas Jentzsch', \\ Ernesto de la Torre ${ }^{2}$, Diana Endara ${ }^{2}$, Florinella Muñoz-Bisesti ${ }^{1,} \bowtie$
}

https://doi.org/10.23939/chcht14.02.161

\begin{abstract}
The incorporation of titanium dioxide and copper onto activated carbon for phenol removal was evaluated. Based on catalyst contents and phenol degradation, four composites were selected and characterized. The results showed that both adsorption and photocatalytic activities were influenced by the presence and arrangement of the catalysts.
\end{abstract}

Keywords: Calgon GRC 20, heterogeneous photocatalysis, phenol, hydroquinone, pyrocatechol, $\mathrm{TiO}_{2} / \mathrm{Cu} /$ carbon composite.

\section{Introduction}

Currently, most of the concern over environmental topics is focused on water pollution due to the social, economic and political implications. Water is a vital resource that must be protected in order to ensure sustainability of all human activities. The demographic growth and the subsequent increase of the production of waste have remarkably contributed to the pollution of water sources. Domestic and industrial (un)treated wastewaters are usually discharged into receiving water bodies, and this could have serious consequences (even in the short term) if the quality of the discharges does not meet certain standards. Perhaps the problem is worse with industrial wastewaters than with those of domestic origin since industrial wastewaters can contain a variety of toxic, xenobiotic and recalcitrant components. One of the most important compounds found in wastewaters of several chemical industries (e.g., petroleum refineries, plastic and varnish) is phenol [1-3].

Phenol is considered a toxic and mutagenic substance that could even be absorbed through the skin

\footnotetext{
${ }^{1}$ Departamento de Ciencias Nucleares, Facultad de Ingeniería Química y Agroindustria,

Escuela Politécnica Nacional, Ladrón de Guevara E11-253, 170525 Quito, Ecuador

${ }^{2}$ Departamento de Metalurgia Extractiva, Facultad de Ingeniería Química y Agroindustria,

Escuela Politécnica Nacional, Ladrón de Guevara E11-253, 170525 Quito, Ecuador

Æflorinella.munoz@epn.edu.ec

(C) Coronel S., Sandoval Pauker C., Vargas Jentzsch P., de la Torre E., Endara D., Muñoz-Bisesti F., 2020
}

[4]. Some researchers have reported the occurrence of phenol and other phenolic compounds in water bodies due to industrial discharge; such is the case of Shiyang river (Northwest China), Pearl River (South China), and Rhine river (Germany) [5-7]. This is a very serious issue since phenol and other phenol derivatives can resist conventional water treatment systems and therefore persist in drinking water $[8,9]$. In addition, the characteristic stability and toxicity of phenol make this substance an interesting candidate for model compound to evaluate the performance of different water treatment systems.

Several reports on the removal of phenol from wastewaters can be found in scientific literature. Studies referred to the removal/degradation of phenol by biological and physicochemical treatments, or a combination of both were extensively reported in the past [10-13]. Considering the advantages and disadvantages of different treatments, advanced oxidation processes (AOPs) are interesting options when it comes to degrade refractory compounds. Most of the AOPs are based on the generation of hydroxyl radicals $(\cdot \mathrm{OH})$ from different sources. Studies on the use of ultraviolet radiation and photocatalysts to generate $\cdot \mathrm{OH}$ radicals showed remarkable results in the degradation of a variety of compounds including dyes, pesticides and other stable pollutants [14-16].

Typical photocatalytic reactions begin when the catalyst absorbs energy and an electron in the valence band $(\mathrm{vb})$ is promoted to the conduction band $(\mathrm{cb})$ with the subsequent generation of a hole in the valence band. The electron-hole pairs $\left(\mathrm{e}^{-} / \mathrm{h}^{+}\right)$can participate in redox reactions with water, organic compounds, hydroxide ions and oxygen in order to oxidize the pollutants [15]. One of the most important photocatalysts is $\mathrm{TiO}_{2}$, but some other options and variations have been evaluated in the last decade $[17,18]$. One of these variations is the production of special composites that combine characteristics of different materials in order to obtain benefits regarding removal and/or degradation of the pollutants [19-22].

In a previous study reported by Andrade et al. [20], a $\mathrm{TiO}_{2} / \mathrm{Cu}$-carbon composite was prepared and used in the photodegradation of phenol under visible light. These authors used a lignocellulosic industrial residue (sisal ropes) to synthesize carbon and, during this process, 
copper was loaded into its structure. The combination of this material with $\mathrm{TiO}_{2}$ resulted in a photocatalyst with a superior performance than $\mathrm{TiO}_{2}$ alone. Based on these results, the possibility of using commercial activated carbons (instead of a lignocellulosic material) for the production of composites with $\mathrm{Cu}$ and $\mathrm{TiO}_{2}$ is attractive since several types of activated carbons are commercially available. This may provide versatility to the treatment systems based on this technology since other mechanisms of reaction could be involved.

In this work, three groups of $\mathrm{TiO}_{2} / \mathrm{Cu}$-carbon composites were obtained from a commercial activated carbon. The influence of changes in the impregnation sequence of copper salts $\left(\mathrm{Cu}\left(\mathrm{NO}_{3}\right)_{2} \cdot 3 \mathrm{H}_{2} \mathrm{O}\right.$ or $\left.\mathrm{CuSO}_{4} \cdot 5 \mathrm{H}_{2} \mathrm{O}\right)$ and $\mathrm{TiO}_{2}$, as well as (calcination) temperature, was evaluated in terms of the composition (contents of $\mathrm{Cu}$ and $\mathrm{Ti}$ ) and the photocatalytic activity of the resulting composites. In order to study the kinetics of the degradation processes, the concentrations of phenol and two primary products (pyrocatechol and hydroquinone) were monitored during the treatments with four selected composites. In addition, the removal of total organic carbon (TOC) provided insights on the degree of phenol mineralization.

\section{Experimental}

\subsection{Reagents}

Commercial activated carbon (Calgon ${ }^{\circledR}$, GRC 20, $\mathrm{d} 80=3.1 \mathrm{~mm}$ ) was used as a supporting material for commercial $\mathrm{TiO}_{2}$ (HOMBITAN AFDC, 99.0\% anatase, $170 \mathrm{~nm}$, Hunstman), $\mathrm{Cu}\left(\mathrm{NO}_{3}\right)_{2} \cdot 3 \mathrm{H}_{2} \mathrm{O}$ (99.0\%, SigmaAldrich), and $\mathrm{CuSO}_{4} \cdot 5 \mathrm{H}_{2} \mathrm{O}$ (99.0\%, Panreac Appli Chem). Phenol aqueous solutions $\left(25-130 \mathrm{mg} \cdot \mathrm{l}^{-1}\right)$ were prepared with phenol (99.0\%, Sigma-Aldrich) and bidistilled water. The $\mathrm{pH}$ values of phenol solutions were adjusted with $10 \% \mathrm{w} / \mathrm{w}$ solution of $\mathrm{HNO}_{3}(65 \%$, Merck). In order to quantify pyrocatechol and hydroquinone, standard aqueous solutions were prepared with pyrocatechol ( $\geq 99 \%$, Sigma-Aldrich) and hydroquinone ( $99 \%$, Baker).

\subsection{Characterization of the Support}

Surface area, volume, and pore diameter of the commercial activated carbon (AC) were measured by the Brunauer-Emmett-Teller (BET) method using a Quantachrome Instruments Nova4200e surface area and pore size analyzer. The particle size distribution of $\mathrm{AC}$ was characterized by ASTM D2862-16 method. The moisture, volatile material, carbon and ash parameters were determined by ASTM D3173M-17a, ASTM D3175-17 and ASTM D3174-12 methods, respectively.

\subsection{Preparation of the Composites}

Several composites were screened to preselect the best ones according to the higher composition of $\mathrm{Cu}$ and $\mathrm{TiO}_{2}$ and the degradation of phenol. For the preparation of the composites, $\mathrm{AC}$ was washed with $\mathrm{HNO}_{3}(10 \%$, w/w) in a stirring system at $100 \mathrm{RPM}$ for $24 \mathrm{~h}$ prior the impregnation of the catalysts.

Three groups of composites were prepared. The composites of the first group were impregnated with $\mathrm{TiO}_{2}$. For this group, the impregnations were carried out using $1 \mathrm{~g}$ of $\mathrm{TiO}_{2}, 100 \mathrm{~g}$ of AC and $350 \mathrm{ml}$ of bi-distilled water. The mixture was stirred for $2 \mathrm{~h}$ and heated $(365 \mathrm{~K}$, the boiling point of water in Quito, Ecuador) until the water was evaporated and then washed with bi-distilled water to eliminate the excess of reagents. A similar procedure was applied to obtain the composites of the second group which were impregnated with copper salts $\left(\mathrm{Cu}\left(\mathrm{NO}_{3}\right)_{2} \cdot 3 \mathrm{H}_{2} \mathrm{O}\right.$ and $\mathrm{CuSO}_{4} \cdot 5 \mathrm{H}_{2} \mathrm{O}$ ). For this group, $20 \mathrm{~g}$ of $\mathrm{Cu}\left(\mathrm{NO}_{3}\right)_{2} \cdot 3 \mathrm{H}_{2} \mathrm{O}$ or $\mathrm{CuSO}_{4} \cdot 5 \mathrm{H}_{2} \mathrm{O}, 100 \mathrm{~g}$ of $\mathrm{AC}$, and $350 \mathrm{ml}$ of bi-distilled water were employed. The mixture was stirred and washed as described above for the first group. For the third group, copper salts and $\mathrm{TiO}_{2}$ were impregnated in different sequences: (i) first the copper salt, afterwards $\mathrm{TiO}_{2}$, (ii) first $\mathrm{TiO}_{2}$, afterwards the copper salt, and (iii) simultaneous impregnation (using $700 \mathrm{ml}$ of bi-distilled water).

After the impregnations, the composites were dried at $383 \mathrm{~K}$ for $2 \mathrm{~h}$. Furthermore, they were calcined in the absence of oxygen at 673,773 , and $873 \mathrm{~K}$. The weight percent of $\mathrm{Ti}$ and $\mathrm{Cu}$ impregnated in each composite was determined by atomic absorption in a Perkin Elmer Analyst 300 flame atomic absorption spectrometer. The composites with the highest content of $\mathrm{Cu}$ and $\mathrm{Ti}$ in each group were preselected for the tests of phenol degradation.

\subsection{Evaluation and Characterization of the Composites}

The photocatalytic activity of the preselected composites was evaluated through the photodegradation of phenol under UV irradiation. A batch scale lab system was built using two UV lamps $(15 \mathrm{~W}, \lambda=254 \mathrm{~nm}$, Sylvania), a vessel, a magnetic stirrer, and a water-cooling system. Samples of $100 \mathrm{ml}$ of phenol solution $\left(25 \mathrm{mg} \cdot \mathrm{l}^{-1}\right)$ were treated in the system for $2 \mathrm{~h}$ using $1 \mathrm{~g} \cdot \mathrm{l}^{-1}$ of the composite. The phenol concentration was measured by the colorimetric method 8047 in a HACH D8 spectrophotometer (as an initial approach).

Based on the tests of phenol degradation, four composites were selected: one composite of the first group (only $\mathrm{TiO}_{2}$ ), one of the second group (only copper salts), and two composites of the third group (one with a content of $\mathrm{Ti}$ higher than the content of $\mathrm{Cu}$ and the other with a content of $\mathrm{Cu}$ higher than the content of Ti). The XRD 
patterns of the selected composites were recorded on a Bruker D8 Advance Diffractometer, and the data were processed using the software Bruker DIFFRAC EVA. The point of zero charge (PZC) of each composite was determined using the method proposed by Newcombe et al. [23]. Moreover, the surfaces of the composites were studied using a Tescan Vega SEM system.

\subsection{Adsorption Capacity and Photocatalytic Activity of the Selected Composites}

Photocatalytic activity and adsorption capacity of the selected composites were studied independently. Adsorption tests were carried out at room temperature $(\sim 293 \mathrm{~K})$ without light exposure. The adsorption for each composite was studied for $25 \mathrm{~h}$ using phenol solutions $\left(50 \mathrm{mg} \cdot 1^{-1}\right)$ and composite concentrations of $1 \mathrm{~g} \cdot l^{-1}$. Then, phenol solutions with different concentrations $(60,70,80$, 90 and $100 \mathrm{mg} \cdot \mathrm{l}^{-1}$ ) were used to build the adsorption isotherms. The concentration of phenol was measured by liquid chromatography on an Agilent L1120 HPLC equipped with a $\mathrm{C} 18$ reverse phase flow column, and a UV/VIS detector $(270 \mathrm{~nm})$.

The photocatalytic activity of the selected composites was evaluated in the batch scale lab system (see Subsection 3.4) using phenol solutions. The $\mathrm{pH}$ value was adjusted to 4.0 according to previous studies [24]. Before the irradiation, a pre-equilibration step was carried out for $24 \mathrm{~h}$ in order to allow the adsorption of phenol. After this step the concentration of phenol was approximately $25 \mathrm{mg} \cdot \mathrm{l}^{-1}$ (this concentration was considered the initial concentration for the photocatalytic essays). The concentrations of phenol and the primary degradation products (pyrocatechol and hydroquinone) were measured at different times up to $24 \mathrm{~h}$ by HPLC. In order to verify the effect of the addition of $\mathrm{Cu}$ on the mineralization of phenol, the removal of total organic carbon (TOC) was measured for the treatments with the composite impregnated with $\mathrm{TiO}_{2}$ and $\mathrm{Cu}$ that showed the highest photocatalytic activity, and the composite impregnated with $\mathrm{TiO}_{2}$.

\section{Results and Discussion}

\subsection{Characterization of Commercial Activated Carbon used as a Support}

The commercial AC was characterized to determine the surface area, volume and pore diameter, moisture, volatile compounds, carbon and ash parameters. The results of the BET analysis showed that the activated carbon support had a specific surface area of $990.9 \mathrm{~m}^{2} \cdot \mathrm{g}^{-1}$, a pore volume of $0.3843 \mathrm{~cm}^{3} \cdot \mathrm{g}^{-1}$ and a pore diameter of $33.92 \AA$. Additionally, a content of carbon $(82.28 \%)$, ash
(5.31\%), moisture $(6.62 \%)$, and volatile compounds $(5.79 \%)$ were determined. These results suggested that the $\mathrm{AC}$ presented the stability and resistance needed for the impregnation of $\mathrm{Cu}$ and $\mathrm{TiO}_{2}$ and would not lose its mechanical properties during the photocatalytic treatment of the phenol solution. Moreover, considering the grainsize of $\mathrm{TiO}_{2}(\sim 170 \mathrm{~nm})$ and the characteristics of $\mathrm{AC}$, it was expected that both $\mathrm{TiO}_{2}$ and $\mathrm{Cu}$ can be impregnated in the external surface of the $\mathrm{AC}$, while the microporosity can be accessible only for $\mathrm{Cu}$ (see Subsection 2.3 for more details).

\subsection{Preparation of the Composites}

As previously mentioned, several composites were prepared and preselected (according to the higher contents of $\mathrm{Cu}$ and/or Ti) for the subsequent evaluation of phenol removal and selection of 4 composites which were characterized and studied in detail.

The contents of $\mathrm{Cu}$ and $\mathrm{Ti}$ of all the composites prepared are summarized in Table 1. It is important to mention that a codification was assigned to each composite in order to simplify the discussion section. The expressions TI, CN and CS are related to titanium dioxide, copper nitrate and copper sulfate, respectively. Also, they are arranged according to the order of impregnation. Note that a capital $\mathrm{S}$ was added at the beginning of the codes for the simultaneous impregnations. In addition, the numbers 4,5 and 6 are related to calcination temperature (673, 773 and 873, respectively).

Based on the results of atomic absorption analyses ten composites were preselected ( 2 of the first and second group and 6 of the third group). The preselected composites are detailed in Table 2.

\subsection{Evaluation of the Composites}

The photocatalytic activity of the preselected composites was evaluated in terms of the phenol removal as depicted in Table 2. For the composites of group 1 $\left(\mathrm{TiO}_{2}\right)$, the phenol removal was $61.8 \%$ using the composite without calcination and $49.6 \%$ using the composite calcined at $773 \mathrm{~K}$. Although it seems that there was an increase of the content of $\mathrm{Ti}$ with temperature (from 0.14 to $0.18 \%$ ), a negative effect on the composites activity was observed, perhaps due to an anatase to rutile phase transformation [4]. For the composites of group 2, the highest removal of phenol (77\%) was achieved with the composite impregnated with $\mathrm{Cu}\left(\mathrm{NO}_{3}\right)_{2}$ calcinated at $873 \mathrm{~K}(4.10 \% \mathrm{Cu})$. Moreover, a removal of $75.5 \%$ was attained using the composite of the third group impregnated with the sequence $\mathrm{Cu}\left(\mathrm{NO}_{3}\right)_{2}-\mathrm{TiO}_{2}$ and a calcination temperature of $873 \mathrm{~K}(3.68 \% \mathrm{Cu}, 0.08 \% \mathrm{Ti})$. The composite prepared by simultaneous impregnation of $\mathrm{Cu}\left(\mathrm{NO}_{3}\right)_{2}$ and $\mathrm{TiO}_{2}$ calcined at $673 \mathrm{~K}(0.22 \% \mathrm{Cu}, 0.52 \%$ 
Ti) reached a phenol removal of $79.6 \%$ (see Subsection 2.4 for more details).

According to the data of phenol photocatalytic degradation, four composites were selected: TI, CN6, CNTI6, and SCNTI4. These composites were characterized, and their adsorption capacity and photocatalytic activity were tested in terms of phenol degradation.

The characterization data of the selected composites are presented in Table 3. As shown in this table, the point of zero charge (PZC) of $\mathrm{AC}$ was lower after the preparation of the composites. This reduction can be attributed to the modification of AC during the impregnation process [25].

XRD patterns of the composites were recorded. The results exhibited the presence of anatase phase in all the composites impregnated with $\mathrm{TiO}_{2}$. Additionally, the presence of copper oxides cuprite $\left(\mathrm{Cu}_{2} \mathrm{O}\right)$, tenorite $(\mathrm{CuO})$ and metallic copper $\left(\mathrm{Cu}^{0}\right)$ was detected.

Table 1

Contents of titanium and copper in activated carbon composites

\begin{tabular}{|c|c|c|c|c|c|c|c|c|c|c|c|}
\hline Group & Code & $\mathrm{Cu}, \%$ & $\mathrm{Ti}, \%$ & Group & Code & $\mathrm{Cu}, \%$ & $\mathrm{Ti}, \%$ & Group & Code & $\mathrm{Cu}, \%$ & $\mathrm{Ti}, \%$ \\
\hline \multirow{4}{*}{$\begin{array}{c}\text { Group } 1 \\
\mathrm{TiO}_{2}\end{array}$} & TI & - & 0.14 & \multirow{4}{*}{$\begin{array}{c}\text { Group } 3 \\
\mathrm{TiO}_{2} \\
\mathrm{Cu}\left(\mathrm{NO}_{3}\right)_{2}\end{array}$} & TICN & 2.09 & 0.09 & \multirow{4}{*}{$\begin{array}{c}\text { Group } 3 \\
\mathrm{CuSO}_{4} \\
\mathrm{TiO}_{2}\end{array}$} & CSTI & 0.24 & 0.25 \\
\hline & TI4 & - & 0.11 & & TICN4 & 1.39 & 0.39 & & CSTI4 & 0.14 & 0.34 \\
\hline & TI5 & - & 0.18 & & TICN5 & 3.97 & 0.07 & & CSTI5 & 0.81 & 0.20 \\
\hline & TI6 & - & 0.16 & & TICN6 & 4.56 & 0.09 & & CSTI6 & 0.09 & 0.05 \\
\hline \multirow{4}{*}{$\begin{array}{c}\text { Group } 2 \\
\mathrm{Cu}\left(\mathrm{NO}_{3}\right)_{2}\end{array}$} & $\mathrm{CN}$ & 1.10 & - & \multirow{4}{*}{$\begin{array}{c}\text { Group } 3 \\
\mathrm{TiO}_{2} \\
\mathrm{CuSO}_{4}\end{array}$} & TICS & 2.14 & 0.14 & \multirow{4}{*}{$\begin{array}{c}\text { Group } 3 \\
\text { Simultaneous } \\
\mathrm{Cu}\left(\mathrm{NO}_{3}\right)_{2} \\
\mathrm{TiO}_{2}\end{array}$} & SCNTI & 2.19 & 0.12 \\
\hline & CN4 & 3.87 & - & & TICS4 & 0.23 & 0.43 & & SCNTI4 & 0.22 & 0.52 \\
\hline & CN5 & 1.37 & - & & TICS5 & 0.70 & 0.13 & & SCNTI5 & 0.67 & 0.30 \\
\hline & CN6 & 4.10 & - & & TICS6 & 0.34 & 0.08 & & SCNTI6 & 0.99 & 0.36 \\
\hline \multirow{4}{*}{$\begin{array}{c}\text { Group } 3 \\
\mathrm{CuSO}_{4}\end{array}$} & $\mathrm{CS}$ & 0.58 & - & \multirow{4}{*}{$\begin{array}{c}\text { Group } 3 \\
\mathrm{Cu}\left(\mathrm{NO}_{3}\right)_{2} \\
\mathrm{TiO}_{2}\end{array}$} & CNTI & 0.77 & 0.38 & \multirow{4}{*}{$\begin{array}{c}\text { Group } 3 \\
\text { Simultaneous } \\
\mathrm{CuSO}_{4} \\
\mathrm{TiO}_{2}\end{array}$} & SCSTI & 3.03 & 0.35 \\
\hline & CS4 & 1.41 & - & & CNTI4 & 1.07 & 0.43 & & SCSTI4 & 0.91 & 0.36 \\
\hline & CS5 & 3.66 & - & & CNTI5 & 2.10 & 0.06 & & SCSTI5 & 2.97 & 0.33 \\
\hline & CS6 & 1.54 & - & & CNTI6 & 3.68 & 0.08 & & SCSTI6 & 1.58 & 0.17 \\
\hline
\end{tabular}

Table 2

Photocatalytic activity of the composites with the highest contents of $\mathrm{Cu}$ and $\mathrm{Ti}$

\begin{tabular}{|c|c|c|c|c|}
\hline Group & Composite description & $\mathrm{Cu}, \%$ & $\mathrm{Ti}, \%$ & Phenol removal, \% \\
\hline \multirow[b]{2}{*}{1} & $\mathrm{TiO}_{2}-\mathrm{NC}(\mathrm{TI})$ & - & 0.14 & 61.8 \\
\hline & $\mathrm{TiO}_{2}-773 \mathrm{~K}(\mathrm{TI} 5)$ & - & 0.18 & 49.6 \\
\hline \multirow{2}{*}{2} & $\mathrm{Cu}\left(\mathrm{NO}_{3}\right)_{2}-873 \mathrm{~K}(\mathrm{CN} 6)$ & 4.10 & - & 77.0 \\
\hline & $\mathrm{CuSO}_{4}-773 \mathrm{~K}(\mathrm{CS} 5)$ & 3.66 & - & 64.5 \\
\hline \multirow{6}{*}{3} & $\mathrm{TiO}_{2}-\mathrm{Cu}\left(\mathrm{NO}_{3}\right)_{2}-873 \mathrm{~K}(\mathrm{TICN} 6)^{\mathrm{a})}$ & 4.56 & 0.09 & 71.3 \\
\hline & $\mathrm{Cu}\left(\mathrm{NO}_{3}\right)_{2}-\mathrm{TiO}_{2}-873 \mathrm{~K}(\mathrm{CNTI} 6)^{\mathrm{a})}$ & 3.68 & 0.08 & 75.5 \\
\hline & 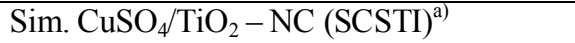 & 3.03 & 0.35 & 43.3 \\
\hline & $\mathrm{TiO}_{2}-\mathrm{CuSO}_{4}-673 \mathrm{~K}(\mathrm{TICS} 4)^{\mathrm{b})}$ & 0.23 & 0.43 & 69.3 \\
\hline & $\mathrm{Cu}\left(\mathrm{NO}_{3}\right)_{2}-\mathrm{TiO}_{2}-673 \mathrm{~K}(\mathrm{CNTI} 4)^{\mathrm{b})}$ & 1.07 & 0.43 & 68.0 \\
\hline & $\mathrm{Sim} . \mathrm{Cu}\left(\mathrm{NO}_{3}\right)_{2} / \mathrm{TiO}_{2}-673 \mathrm{~K}(\mathrm{SCNTI} 4)^{b)}$ & 0.22 & 0.52 & 79.6 \\
\hline
\end{tabular}

Notes: ${ }^{\text {a) }} \% \mathrm{Cu}>\% \mathrm{Ti} ;{ }^{\text {b) }} \% \mathrm{Ti}>\% \mathrm{Cu}$

Table 3

Characterization of the composites with the highest photocatalytic activity

\begin{tabular}{|c|c|c|c|c|}
\hline Composite & $\mathrm{SBET}, \mathrm{m}^{2} / \mathrm{g}$ & $V_{\text {micro }} \mathrm{cm}^{3} / \mathrm{g}$ & $\Phi_{\text {micro }}, \AA$ & PZC \\
\hline AC & 990.90 & 0.3843 & 33.92 & 10.4 \\
\hline TI & 1031.55 & 0.4200 & 11.78 & 8.5 \\
\hline CN6 & 965.59 & 0.3675 & 5.63 & 8.6 \\
\hline CNTI6 & 965.07 & 0.3530 & 12.32 & 8.4 \\
\hline SCNTI4 & 970.34 & 0.4460 & 11.78 & 8.2 \\
\hline
\end{tabular}


In addition, SEM images and a chemical mapping of the composites were obtained to evaluate the impregnation of the catalysts (Fig. 1). For the composite impregnated with $\mathrm{TiO}_{2}$ (Fig. 1a), agglomerates of the catalyst at specific sites of the $\mathrm{AC}$ were observed. On the other hand, the composite impregnated with $\mathrm{Cu}\left(\mathrm{NO}_{3}\right)_{2}$ (Fig. 1b) showed that $\mathrm{Cu}$ was dispersed over the $\mathrm{AC}$ surface. The SEM image of the composite impregnated with sequence $\mathrm{Cu}\left(\mathrm{NO}_{3}\right)_{2}-\mathrm{TiO}_{2}$ (Fig. 1c) presented the same distribution for $\mathrm{Cu}\left(\mathrm{NO}_{3}\right)_{2}$ as for $\mathrm{CN} 6$. However, only a small amount of $\mathrm{TiO}_{2}$ can be observed which can be explained by the fact that the AC surface which was already covered with $\mathrm{Cu}$, did not have enough space for $\mathrm{TiO}_{2}$. For the simultaneous impregnation of $\mathrm{Cu}\left(\mathrm{NO}_{3}\right)_{2}$ and $\mathrm{TiO}_{2}$ (Fig. 1d), the image showed that both $\mathrm{Cu}$ and $\mathrm{TiO}_{2}$ were dispersed over the AC surface.

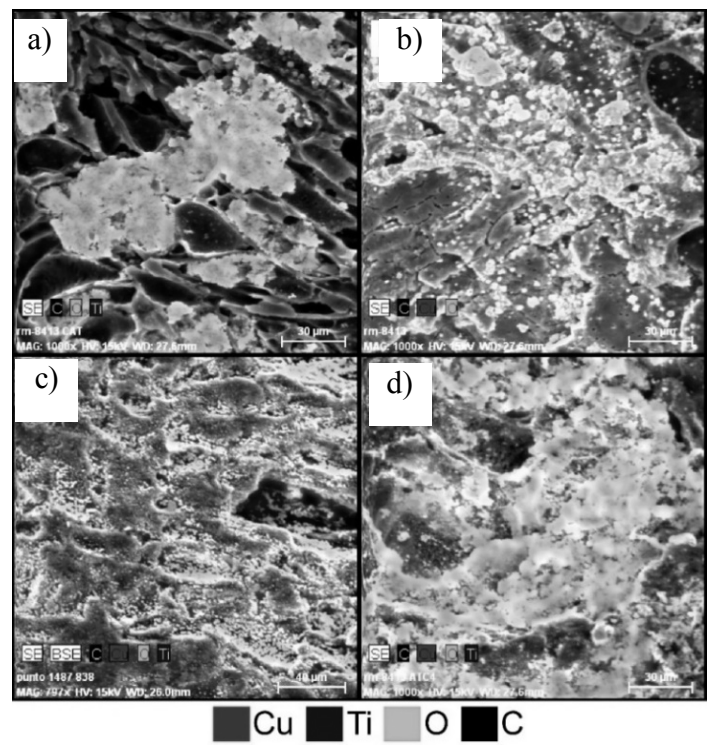

Fig. 1. SEM images and chemical mapping of TI (a); CN6 (b), CNTI6 (c) and SCNTI4 (d). Magnification of $1 \cdot 10^{3} \times$ for $(a, d)$ and $800 \times$ for $(b, c)$

\subsection{Adsorption Capacity and Photocatalytic Activity of the Selected Composites}

Once characterized, the adsorption capacity and photocatalytic activity of the composites were studied. In the case of adsorption, phenol solutions $\left(50 \mathrm{mg} \cdot \mathrm{l}^{-1}\right)$ and a composite concentration of $1 \mathrm{~g} \cdot \mathrm{l}^{-1}$ were used to study the adsorption kinetics over $25 \mathrm{~h}$. The results of these tests showed that for all composites the time required to attain equilibrium was $24 \mathrm{~h}$. Once the equilibrium time was determined, adsorption isotherms of $\mathrm{AC}$ and each composite (Fig. 2) were constructed using different concentrations of phenol $\left(60,70,80,90\right.$ and $\left.100 \mathrm{mg} \cdot \mathrm{l}^{-1}\right)$ and a loading of composites of $1 \mathrm{~g} \cdot 1^{-1}$. Moreover, Langmuir and Freundlich isotherm models were used to describe the adsorption process. According to $R^{2}$ values $(0.97-0.99)$, a better fit was obtained with the Langmuir model. Other studies have also applied a Langmuir model to describe the adsorption of phenol onto AC [26].

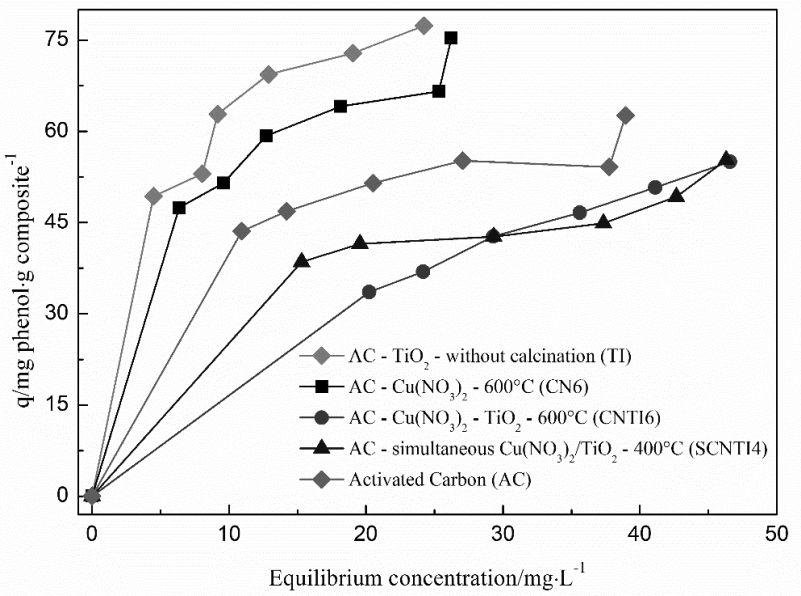

Fig. 2. Phenol adsorption isotherms from aqueous solutions on the studied composites $(T=293 \mathrm{~K} ; \mathrm{pH}=4.0)$

The maximum adsorption capacities $\left(q_{m}\right)$ and Langmuir constants $(b)$ of the composites and $\mathrm{AC}$ alone were determined. Also, a statistical analysis was carried out to determine whether the presence and arrangement of the catalysts influenced the adsorption of phenol onto AC. The calculated parameters are presented in Table 4. The statistical analysis showed that the maximum adsorption capacities of TI, CN6 and CNTI6 were higher than the adsorption capacity of AC alone $\left(q_{m}=67.80 \mathrm{mg}\right.$ phenol.g composite $\left.{ }^{-1}\right)$. Furthermore, there were no significant differences between the maximum adsorption capacities of AC and SCNTI4. These results suggested that the adsorption of phenol over the composites was modified by both the presence and arrangement of $\mathrm{TiO}_{2}$ and $\mathrm{Cu}$ (i.e., metallic copper and/or oxides) over the surface of AC. Considering the presence of the catalysts, other studies have reported the capacity of $\mathrm{TiO}_{2}$ and copper species as adsorbents of organic compounds. For instance, Shtykova et al. [27] found that some organic compounds, such as medetomidine, imidazole, diuron, among others can be adsorbed in copper oxides. Moreover, Bekkouche et al. [28] mentioned that the presence of $\mathrm{TiO}_{2}$ in $\mathrm{AC}$ could increase the adsorption of phenol. On the other hand, the arrangement of the catalysts over the surface of AC could also modify the adsorption. As explained before, $\mathrm{TiO}_{2}$ could occupy only the external surface of AC (see Fig. 1) due to its grain size $(\sim 170 \mathrm{~nm})$. As a result, this catalyst could cover the microporosity of $\mathrm{AC}$ and limit the adsorption although its presence could also improve the photocatalytic activity (Table 4). This fact could explain why the maximum adsorption capacities of AC and SCNTI4 are statistically equal. 
Langmuir constants and photocatalytic degradation of phenol

\begin{tabular}{|c|c|c|c|c|c|}
\hline \multirow{2}{*}{ Composite } & \multicolumn{3}{|c|}{ Langmuir isotherm } & \multicolumn{2}{c|}{ Photocatalysis } \\
\cline { 2 - 6 } & $q_{m}, \mathrm{mg} \cdot \mathrm{g}^{-1}$ & $b, 1 \cdot \mathrm{mg}^{-1}$ & $R^{2}$ & $k \cdot 10^{4}, \mathrm{~min}^{-1}$ & Phenol removal, \% \\
\hline AC & 67.80 & 0.158 & 0.972 & - & - \\
\hline TI & 90.56 & 0.168 & 0.977 & 9.38 & 76.66 \\
\hline CN6 & 85.84 & 0.176 & 0.966 & 12.40 & 84.24 \\
\hline CNTI6 & 107.03 & 0.015 & 0.990 & 14.00 & 87.59 \\
\hline SCNTI4 & 63.54 & 0.087 & 0.938 & 18.00 & 92.26 \\
\hline
\end{tabular}

Fig. 3 shows the photocatalytic degradation of phenol using the composites studied. For all composites, the reactions followed the pseudo-first order kinetics. The statistical analysis showed that the highest rate constants (see Table 4) were achieved using SCNTI4 $(0.22 \% \mathrm{Cu}$, $0.52 \% \mathrm{Ti})$ and CNTI6 $(3.68 \% \mathrm{Cu}, 0.08 \% \mathrm{Ti})$. A positive effect of the impregnation of both catalysts $\left(\mathrm{Cu}\right.$ and $\left.\mathrm{TiO}_{2}\right)$ was observed. This effect has been reported in other studies. For instance, Sohrabi and Akhlaghian [29] found that $\mathrm{Cu}^{2+}$ ions can be adsorbed on the surface of $\mathrm{TiO}_{2}$ and act as electron trapping centers which increase the $\left(\mathrm{e}^{-} / \mathrm{h}^{+}\right)$ pairs formation efficiency and improves the generation of - OH radicals. Also, other studies found that the combination of $\mathrm{TiO}_{2}$ and copper oxides could improve the photocatalytic degradation of phenol [30, 31].

The composite impregnated only with $\mathrm{Cu}$ (CN6, $4.10 \% \mathrm{Cu}$ ) also presented photocatalytic activity $\left(k=12.4 \cdot 10^{-4} \mathrm{~min}^{-1}\right)$. This result could be explained by the presence of copper oxides on the surface of $\mathrm{AC}$ and the leaching of copper ions into the solution because both copper oxides and ions seem to have photocatalytic activity. Previous studies have tested the photocatalytic activity of copper oxides. For example, $\mathrm{CuO}$ nanoparticles have been applied in the past to remove other recalcitrant pollutants such as rhodamine B [32, 33]. Regarding the presence of $\mathrm{Cu}^{2+}$ ions, it should be mentioned that these ions can be leached from the composites due to the acidic conditions of the treatment [34]. In the present study, the leaching of $\mathrm{Cu}$ was confirmed by measuring its concentration in the treated phenol solutions by an atomic absorption analysis. For the case of $\mathrm{CN} 6$, about $5 \%$ of $\mathrm{Cu}$ impregnated on the composite was leached. Moreover, the photocatalytic activity of these ions was tested by irradiating samples of phenol solutions $(60 \mathrm{mg} / \mathrm{l})$ with UV radiation using only $\mathrm{Cu}\left(\mathrm{NO}_{3}\right)_{2}$, and a phenol removal of $5.28 \%$ was attained during the first hour of treatment.

In order to determine if the presence of copper could have influence over the formation of primary degradation products of phenol, the evolution of pyrocatechol (PC) and hydroquinone (HY) was measured. As shown in Fig. 4, both intermediates were produced in the case of the composite impregnated only with $\mathrm{TiO}_{2}$ (TI). Also, it was observed that the production of PC was higher than the formation of HY. These results were in agreement with the ones presented by Velasco et al. [35] who found the same intermediates and trend $(\mathrm{PC}>\mathrm{HY})$ when $\mathrm{TiO}_{2}$ was supported in AC. On the other hand, $\mathrm{HY}$ was not detected for the composites which presented copper in their composition. In these cases, PC was the primary intermediate. This can be explained because $\mathrm{Cu}$ presents a regioselectivity towards the formation of $\mathrm{PC}$ as mentioned by Andrade et al. [20]. As a result, it was confirmed that the presence of $\mathrm{Cu}$ could not only improve the phenol removal but influence over the path of the degradation reaction. Future studies should also be focused on the degradation products of PC and HY in order to have a better understanding of this phenomenon.

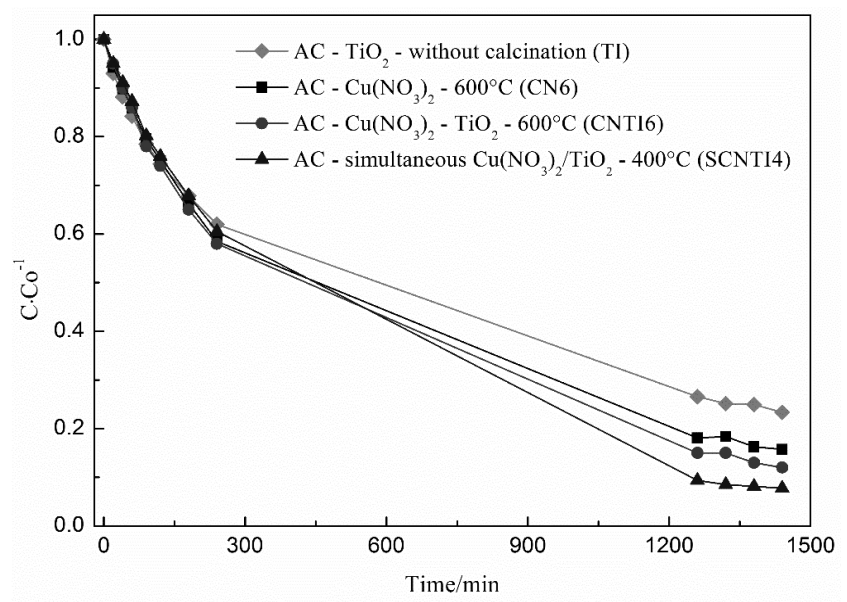

Fig. 3. Photocatalytic degradation of phenol using TI, CN6, CNTI6 and SCNTI4 composites $\left([\mathrm{Phenol}]_{0}=\sim 25 \mathrm{mg} \cdot \mathrm{l}^{-1} ; T=293 \mathrm{~K} ; 1 \mathrm{~g}\right.$ composite $\left.\cdot \mathrm{l}^{-1}\right)$

The removal of total organic carbon (TOC) was measured for the treatments using TI and SCNTI4 (which presented the highest photocatalytic activity). A TOC removal of 78.48 and $87.84 \%$ was obtained after $24 \mathrm{~h}$ of treatment using TI and SCNTI4, respectively. This suggests that the presence of copper can increase the mineralization of phenol.

Considering the results presented in this study, the impregnation of $\mathrm{Cu}$ and $\mathrm{TiO}_{2}$ on a commercial $\mathrm{AC}$ could 
be an interesting alternative for the removal of recalcitrant compounds such as phenol. A first approach to the immobilization and applicability of these kinds of composites are provided. Future studies should also be addressed to establish the influence of specific factors such as pretreatment of $\mathrm{AC}$, calcination temperature, particle size of the catalysts, among others on the preparation and performance of the composites.
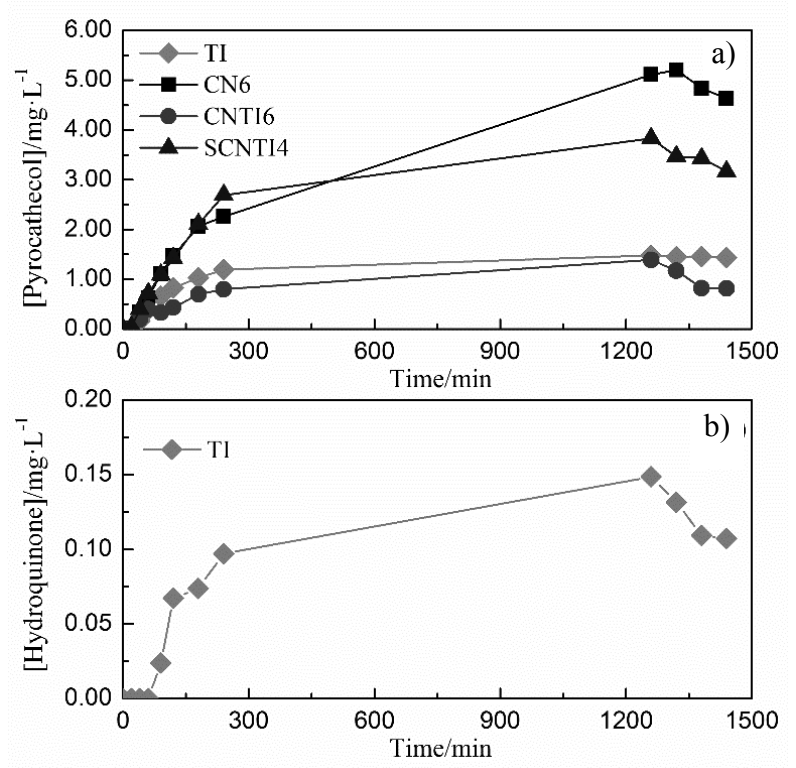

Fig. 4. Evolution of phenol primary degradation products: pyrocatechol (a) and hydroquinone (b) by heterogeneous photocatalysis using the composites studied

\section{Conclusions}

Several composites were prepared following different order of impregnation of $\mathrm{Cu}\left(\mathrm{NO}_{3}\right)_{2} / \mathrm{CuSO}_{4}$ and $\mathrm{TiO}_{2}$. According to the results of atomic absorption analyses and phenol removals, four composites were selected (TI, CN6, CNTI6, and SCNTI4). The XRD patterns of the selected composites showed the presence of copper species and $\mathrm{TiO}_{2}$ (as an anatase). For the composites impregnated only with $\mathrm{TiO}_{2}$ and $\mathrm{Cu}\left(\mathrm{NO}_{3}\right)_{2}$, SEM images showed the occurrence of $\mathrm{TiO}_{2}$ agglomerations, and $\mathrm{Cu}$ dispersed over the surface of $\mathrm{AC}$. Also, both $\mathrm{TiO}_{2}$ and $\mathrm{Cu}$ were dispersed when the catalysts were impregnated simultaneously.

The adsorption capacity of the composites could be modified by the presence of $\mathrm{TiO}_{2}$ and $\mathrm{Cu}$ and the arrangement of the catalysts over the surface of AC. The highest rate constants were achieved using the composites impregnated with both catalysts $\left(k_{\mathrm{SCNTI}}=18 \cdot 10^{-4} \mathrm{~min}^{-1}\right.$, $\left.k_{\mathrm{CNTI}}=14 \cdot 10^{-4} \mathrm{~min}^{-1}\right)$. Therefore, a positive effect of the impregnation of $\mathrm{Cu}$ and $\mathrm{TiO}_{2}$ was observed. Furthermore, the composite impregnated only with $\mathrm{Cu}(\mathrm{CN} 6,4.10 \%$ $\mathrm{Cu})$ presented a photocatalytic activity $\left(k=12.4 \cdot 10^{-4} \mathrm{~min}^{-1}\right)$. This behavior was explained by the presence of copper species onto the composites and $\mathrm{Cu}^{2+}$ ions in the solutions.

The study of the evolution of the intermediates pyrocatechol (PC) and hydroquinone (HY) showed that PC and HY were produced using TI, while only PC was produced using the composites with $\mathrm{Cu}$ in their composition. TOC removal values were $84.84 \%$ using the combination $\mathrm{AC} / \mathrm{Cu} / \mathrm{TiO}_{2}$ and $78.48 \%$ for the combination $\mathrm{AC} / \mathrm{TiO}_{2}$. Therefore, the combination $\mathrm{AC} / \mathrm{Cu} / \mathrm{TiO}_{2}$ increases the mineralization of phenol and its intermediates. According to the results, it was found that the impregnation of $\mathrm{Cu}$ and $\mathrm{TiO}_{2}$ on a commercial $\mathrm{AC}$ could be an interesting alternative for the removal of recalcitrant compounds such as phenol.

\section{Acknowledgements}

The authors would like to thank the financial support provided by Escuela Politécnica Nacional through the project PIMI-14-13 "Study of the application of $\mathrm{TiO}_{2}$ supported on activated carbon on the photocatalytic degradation of dyes and phenols".

\section{References}

[1] Arutchelvan V., Kanakasabai V., Nagarajan S. et al.: J. Hazard. Mater., 2005, 127, 238.

https://doi.org/10.1016/j.jhazmat.2005.04.043

[2] Kumar A., Kumar S., Kumar S.: Biochem. Eng. J., 2005, 22,

151. https://doi.org/10.1016/j.bej.2004.09.006

[3] Bandhyopadhyay K., Das D., Bhattacharyya P. et al.: Biochem.

Eng. J., 2001, 8, 179. https://doi.org/10.1016/S1369-

$703 \mathrm{X}(01) 00101-2$

[4] Dobrosz-Gómez I., Gómez-García M., López Zamora S. et al.: Comptes Rendus Chim., 2015, 18, 1170.

https://doi.org/10.1016/j.crci.2015.03.006

[5] Ma J., Ding Z., Wei G. et al.: J. Environ. Manage., 2009, 90,

1168. https://doi.org/10.1016/j.jenvman.2008.05.007

[6] Peng X., Yu Y., Tang C. et al.: Sci. Total Environ., 2008, 397,

158. https://doi.org/10.1016/j.scitotenv.2008.02.059

[7] Schwarzbauer J., Heim S.: Water Res., 2005, 39, 4735.

https://doi.org/10.1016/j.watres.2005.09.029

[8] Stackelber P., Furlong E., Meyer M. et al.: Sci. Total Environ., 2004, 329, 99. https://doi.org/10.1016/j.scitotenv.2004.03.015

[9] Stackelberg P., Gibs J., Furlong E. et al.: Sci. Total Environ., 2007, 377, 255. https://doi.org/10.1016/j.scitotenv.2007.01.095

[10] Sivasubramanian S., Namasivayam S.: J. Environ. Chem. Eng., 2015, 3, 243. https://doi.org/10.1016/j.jece.2014.12.014

[11] Oller I., Malato S., Sánchez-Pérez J.: Sci. Total Environ., 2011, 409, 4141. https://doi.org/10.1016/j.scitotenv.2010.08.061

[12] Lin S., Juang R.: J. Environ. Manage., 2009, 90, 1336. https://doi.org/10.1016/j.jenvman.2008.09.003

[13] Lefebvre O., Moletta R.: Water Res., 2006, 40, 3671. https://doi.org/10.1016/j.watres.2006.08.027

[14] Brooms T., Onyango M., Ochieng A.: J. Water Chem.

Technol., 2017, 39, 155.

https://doi.org/10.3103/S1063455X17030067 
[15] Ibhadon A., Fitzpatrick P.: Catalysts, 2013, 3, 189. https://doi.org/10.3390/catal3010189

[16] Kulkarni M., Thakur P.: Chem. Chem. Technol., 2010, 4, 265. [17] Liu J., Zhang G.: Phys. Chem. Chem. Phys., 2014, 16, 8178. https://doi.org/10.1039/c3cp54146k

[18] Zangeneh H., Zinatizadeh A., Habibi M. et al.: J. Ind. Eng. Chem., 2015, 26, 1. https://doi.org/10.1016/j.jiec.2014.10.043

[19] Benjwal P., Kar K.: J. Environ. Chem. Eng., 2015, 3, 2076. https://doi.org/10.1016/j.jece.2015.07.009

[20] Andrade M., Carmona R., Mestre A. et al.: Carbon, 2014, 76, 183. https://doi.org/10.1016/j.carbon.2014.04.066

[21] Chen Y., Huang W., He D. et al.: ACS Appl. Mater. Interfaces, 2014, 6, 14405. https://doi.org/10.1021/am503674e

[22] Khalid N., Ahmed E., Hong Z. et al.: Ceram. Int., 2013, 39,

7107. https://doi.org/10.1016/j.ceramint.2013.02.051

[23] Newcombe G., Hayes R., Drikas M.: Colloids Surface A, 1993, 78, 65. https://doi.org/10.1016/0927-7757(93)80311-2

[24] Nahar M., Hasegawa K., Kagaya S.: Chemosphere, 2006, 65, 1976. https://doi.org/10.1016/j.chemosphere.2006.07.002

[25] Carabineiro S., Thavorn-Amornsri T., Pereira M. et al.: Water Res., 2011, 45, 4583. https://doi.org/10.1016/j.watres.2011.06.008 [26] Özkaya B.: J. Hazard. Mater., 2006, 129, 158. https://doi.org/10.1016/j.jhazmat.2005.08.025

[27] Shtykova L., Fant C., Handa P. et al.: Prog. Org. Coatings, 2009, 64, 20. https://doi.org/10.1016/j.porgcoat.2008.07.005

[28] Bekkouche S., Bouhelassa M., Hadj Salah N. et al.:

Desalination, 2004, 166, 355.

https://doi.org/10.1016/j.desal.2004.06.090

[29] Sohrabi S., Akhlaghian F.: Process Saf. Environ. Prot., 2016,

99, 120. https://doi.org/10.1016/j.psep.2015.10.016
[30] Colón G., Maicu M., Hidalgo M. et al.: Appl. Catal. B, 2006, 67, 41. https://doi.org/10.1016/j.apcatb.2006.03.019

[31] Li J., Liu L., Yu Y. et al.: Electrochem. Commun., 2004, 6, 940. https://doi.org/10.1016/j.elecom.2004.06.008

[32] Liu J., Jin J., Deng Z. et al.: J. Colloid Interface Sci., 2012, 384, 1. https://doi.org/10.1016/j.jcis.2012.06.044

[33] Li Y., Yang X., Rooke J. et al.: J. Colloid Interface Sci., 2010, 348, 303. https://doi.org/10.1016/j.jcis.2010.04.052

[34] Huanosta-Gutiérrez T., Dantas R., Ramírez-Zamora R. et al.: J. Hazard. Mater., 2012, 213-214, 325.

https://doi.org/10.1016/j.jhazmat.2012.02.004

[35] Velasco L., Tsyntsarski B., Petrova B. et al.: J. Hazard. Mater., 2010, 184, 843. https://doi.org/10.1016/j.jhazmat.2010.08.118

Received: September 27, 2018 / Revised: October 22, 2018 /

Accepted: December 28, 2018

\section{ДІОКСИД ТИТАНУ/МІДЬ/КАРБОНОВІ КОМПОЗИТИ ДЛЯ ФОТОКАТАЛИТИЧНОЇ ДЕГРАДАЦЇ̈ ФЕНОЛУ}

Анотація. Досліджено імпрегнацію діоксиду титану та міді на активоване вугілля (АС) з метою видалення фенолу. 3 урахуванням кількості каталізатора і ступеня деградації фенолу було обрано та охарактеризовано чотири композити. Встановлено, шео присутність та склад каталізаторів впливають як на адсорбиію, так і на фотокаталітичну активність.

Ключові слова: Calgon GRC 20, гетерогенний фото-

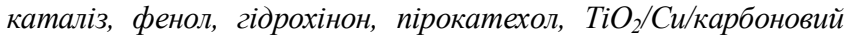
композит. 